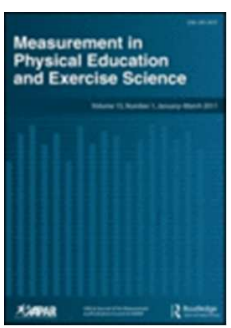

\title{
Validity of a contact mat and accelerometric system to assess countermovement jump
}

\begin{tabular}{|c|c|}
\hline Journal: & Measurement in Physical Education and Exercise Science \\
\hline Manuscript ID & HMPE-2017-0080.R3 \\
\hline Manuscript Type: & Original Article \\
\hline Keywords: & accelerometry, countermovement jump, performance, force plate \\
\hline
\end{tabular}


1 Title:

2 Validity of a contact mat and accelerometric system to assess countermovement jump from

3 flight time

4

5 Submission type: Original investigation

6

7 Running head: Validation of systems for CMJ

8

9

10 


\section{Abstract}

12 Countermovement jump (CMJ) height is an important parameter in physical performance.

13 This study compared CMJ height measured using ChronoJump contact mat (CJ), and

14 Myotest accelerometer (MT) systems with a force platform (FP). Thirty recreationally-active

15 adults $(32.1 \pm 10.4$ years, $75.9 \pm 12.0 \mathrm{~kg}, 173.2 \pm 6.3 \mathrm{~cm})$ completed a CMJ protocol where

16 height was simultaneously recorded using the three systems. CJ and MT measures were

17 strongly and significant correlated $(r=0.65,0.66$, respectively; $p<0.05)$ with FP. CJ-derived

18 measures were not significantly different to FP measures $(p>0.05)$, yet MT-derived

19 measures were significantly different from those obtained using the FP $(p<0.05)$. Systematic

20 bias was observed between FP and the $\mathrm{CJ}$ and between FP and MT. This study demonstrate

21 the validity of $\mathrm{CJ}$ and MT systems for the assessment of CMJ height. Systematic bias and

22 between-device differences in measurement should be considered when interpreting and

23 comparing data from these devices.

Keywords: accelerometry; countermovement jump; performance; force plate 
Introduction

Assessment of lower limb functional performance is important in athletic, and non-

athletic populations. A commonly used measure of lower limb functional performance is the countermovement jump (CMJ) (Comfort, Stewart, Bloom, \& Clarkson, 2014; FernandezSantos, Ruiz, Cohen, Gonzalez-Montesinos, \& Castro-Pinero, 2015; Holsgaard Larsen,

Caserotti, Puggaard, \& Aagaard, 2007; Janot, Beltz, \& Dalleck, 2015; Rittweger, Schiessl,

Felsenberg, \& Runge, 2004), which relies on the ability of the lower limb muscle groups to elevate the body's centre of gravity, and is considered a measure of lower body power (Shetty \& Etnyre, 1989). Among athletic populations, there is a strong association between Wisloff, Castagna, Helgerud, Jones, \& Hoff, 2004) and weightlifting (Carlock et al., 2004). CMJ performance has also been used to assess functional capacity in older adults (Holsgaard

47 Larsen et al., 2007; Rittweger et al., 2004). Given the associations with functional performance in a variety of populations, valid and reliable measures of CMJ which can be used in field or clinical settings are important. assessment of CMJ performance characteristics (Mauch et al, 2014). However, due to their 
54 academies and institutes of sport. Coaches and clinicians working in the field seek

55 instruments that provide valid and reliable measure of $\mathrm{CMJ}$ performance, without the cost

56 and complexity associated with laboratory- or elite sport-based tools. In response to this

57 need, and with the emergence of novel technologies, a number of portable devices are now

58 available to assess CMJ height including contact mats (Pagaduan \& De Blas, 2004),

59 photoelectric cells (Bosquet, Berryman, \& Dupuy, 2009), smart phone applications

60 (Balsalobre-Fernández, Glaister, \& Lockey, 2015) and accelerometric systems (Casartelli,

61 Muller, \& Maffiuletti, 2010). Among these devices, the Myotest (Myotest SA, Sion,

Switzerland) (MT) and ChronoJump (Bosco Systems, Madrid, Spain) (CJ) are among the options available to field based practitioners.

The MT uses an accelerometer which is attached at waist level via a purpose built Velcro belt (Casartelli et al., 2010; Castagna et al., 2013; Choukou, Laffaye, \& Taiar, 2014). The MT calculates $\mathrm{CMJ}$ height based on the acceleration of the centre of mass during the vertical displacement (Castagna et al., 2013). Previous research examining the validity

69 (Casartelli et al., 2010; Choukou et al., 2014) and reliability (Choukou et al., 2014) of the MT has resulted in variable outcomes, dependant on the comparator, and the model of Myotest device. In contrast to the accelerometer-based MT, the $\mathrm{CJ}$ system consists of a contact mat and timing device, which calculates CMJ height from flight time, using standard equations

73 (de Blas, Riu, del Amo, \& Bálic, 2012; Pagaduan \& De Blas, 2004). De Blas and colleagues

74 (2012) describe the development and validity of the CJ to assess flight time, using a

75 fibreglass contact mat. However, like the MT, studies examining the validity of contact mat systems are dependent on the type of mat and comparator device (García-López, Morante, 
77 Ogueta-Alday, \& Rodríguez-Marroyo, 2013). Data such as these make it difficult to confirm

78 the usefulness of portable devices such as MT and CJ to determine CMJ performance, and

79 subsequently make recommendations to clinicians and coaches.

\section{0}

81 One method to directly compare devices with the gold-standard FP, is to perform

82 CMJs on a FP overlayed with a contact mat system, while the performer wears the MJ

83 accelerometer. Such a study would allow direct, simultaneous comparison of both devices

84 with the FP and therefore provide useful information to coaches as clinicians as to the

85 suitability of each device for use in the field. Therefore the aim of the present study was to

86 compare the $\mathrm{CMJ}$ height obtained from the MT and $\mathrm{CJ}$ compared to a gold-standard force

87 platform in a broader population. 
90

$91 \quad$ Subjects

92

93

94

95

96

97

98

99

100

101

102

103

104

105

106

107

108

109

110

111

\section{Design}

Methods

Thirty recreationally active adults from the University community were recruited via face to face contact. For the purpose of the present study, recreationally active was defined as having been engaged in regular sport or recreational activities for a minimum of 12 months prior to inclusion in the study. An overview of the study outlining the purpose, and the potential risks and benefits of participation was provided to all subjects. All subjects were screened for injury and health concerns that may have impeded study participation using Stage 1 of the Adult Pre-exercise Screening System (APSS) (ESSA, 2011) prior to participation, and written informed consent was obtained from all subjects. The study was approved by the Institutional Human Research Ethics Review panel prior to the commencement of the study.

A cross sectional, comparative design was used. CMJ performance (jump height) was simultaneously assessed using $\mathrm{CJ}$ and MT, with both methods compared to the FP. For the $\mathrm{CJ}$ and $\mathrm{FP}, \mathrm{CMJ}$ performance was determined from flight time using the following equation; $h=t^{2} \times 1.22625$ (Bosco, Luhtanen, \& Komi, 1983). For the MT, CMJ height was determined using proprietary software. To ensure the generalisability of our findings, a convenience sample from the local University community was used as subjects.

Methodology 
Following assessment of body mass and height, subjects completed a standardised

warm-up protocol comprising 5-minutes cycling at 50W on a Monark 828e cycle ergometer

(Monark Exercise AB, Vansbro, Sweden), followed by 5-minutes of static and dynamic

stretching of the quadriceps, hamstrings and gastrocnemius/soleus muscles. Subjects then

performed three $\mathrm{CMJ}$ attempts, separated by 60 seconds rest, which acted as familiarisation

attempts. For each of the three warm up attempts, the intensity increased with each

attempt until maximal effort was exerted on the final attempt of the warm-up. For the final

warm up, and for each testing attempt, subjects were instructed to stand erect, with the

feet placed shoulder width apart. Commencing with the hands on the hips, the subject

performed a partial squat to a self-determined depth, followed by a rapid amortisation

phase and explosive concentric phase in attempt to maximise vertical displacement of the

body. Following the completion of warm up attempts, two maximal effort trials were

recorded and the mean of the two trials was used for subsequent analysis. Each attempt

was visually inspected by a member of the research team to ensure correct technique and

landing position. No repeat attempts were required for any participant.

Following a further 3-minute rest, subjects performed two maximal effort CMJ

attempts, separated by 3-minute of passive (seated) rest. Subjects stood on an AMTI force

plate (BP600900-1000, Advanced Mechanical Technology Incorporated, Watertown, MA),

interfaced with an AMTI MSA-6 amplifier (Advanced Mechanical Technology Incorporated,

132 Watertown, MA). Data were sampled at $1000 \mathrm{~Hz}$, filtered using a $2^{\text {nd }}$ order low pass

133 Butterworth filter with a cut-off frequency of $10 \mathrm{~Hz}$, and data were collected for 5 seconds

134 using custom written Labview software (Version 2013, National Instruments, Austin, TX). 
$135 \mathrm{CMJ}$ height was calculated from flight time using the following equation; $h=\mathrm{t}^{2} \times 1.22625$

136 (Bosco et al., 1983). This method shows strong correlation with a modified Wingate test

$137(r=0.87)$ and $60 \mathrm{~m}$ sprint $(r=0.86)$. The force plate was zeroed prior to the participant

138 standing on the force plate and flight time was defined as the time the vertical ground

139 reaction force (vGRF) was below 10N (Linthorne, 2001).

140

141 The force plate was overlaid with a Din A2 $(420 \times 594 \mathrm{~mm})$ sized contact mat (Bosco

142 Systems, Madrid, Spain) connected to a Chronopic 3 timing interface (Bosco Systems,

143 Madrid, Spain). Data were collected using Chronojump software (Version 1.6.1.0; Bosco

144 Systems, Madrid, Spain). For this type of device, the contact mat operates as a simple on/off

145 switch and triggers timing of the duration the switch is in the closed position such as when a

146 participant is standing on the contact mat, or in the open position; for example when a

147 participant is in the air as in the performance of a CMJ. Timing is based on the internal clock

148 of the computer on which the software is installed.

For each CMJ attempt, subjects also wore a Myotest Pro accelerometer system

(Myotest SA, Sion, Switzerland), secured over the subject's right hip using the proprietary

152 elasticized band in accordance with manufacturer's instructions. The Myotest Pro is a small

$153(54.2 \times 10.7 \times 102.5 \mathrm{~mm})$ light weight $(59 \mathrm{~g})$ device containing a triaxial accelerometer $( \pm 8 \mathrm{~g})$

154 which records acceleration at $500 \mathrm{~Hz}$. Prior to use, the Myotest Pro was programed with the

155 subjects height and weight using Myotest Pro software (Version 1.988, Myotest SA, Sion,

156 Switzerland). For the Myotest Pro, CMJ height was determined using proprietary software.

157 The exact method by which the MT determines CMJ height is unclear, however, Choukou 
and colleagues (2013) report flight time as the time between maximal vertical velocity and

159

160

161

162

163

164

165

166

167

168

169

170

171

172

173

174

175

176

177

178

179

180

minimal vertical velocity after touchdown, which must in turn be derived from the integration of acceleration data.

\section{Statistical analysis}

Descriptive statistics (mean \pm standard deviation (SD)) were used to report subject and jump characteristics. Normality was assessed by Kolmogorov-Smirnov test, and skewness and kurtosis z-scores. Pearson's correlations were used to independently examine the validity of the $\mathrm{CJ}$ and $\mathrm{MT}$ devices, and interpreted as $0.00-0.19$ = very weak, $0.20-0.39$ = weak, $0.40-0.59=$ moderate, $0.60-0.79=$ strong, and $0.80-1.00=$ very strong $($ Evans, 1996). Fisher's r-z transformations were used to examine the significance of any difference between the correlation coefficients. Differences in mean $\mathrm{CMJ}$ performance between $\mathrm{CJ}$ and FP, and between MT and FP were examined using paired samples t-tests, with Bonferroni adjustments for multiple comparisons. The magnitude of difference between mean jump heights were also assessed using Cohen's $d$ where $d>0.8$ is a large effect, $d=0.5-0.8$ is a moderate effect; $d=0.2-0.5$ is a small effect; and $d<0.2$ is a trivial effect (Cohen, 1988).

Finally, agreement between $\mathrm{CJ}$ and FP, and between MT and FP were examined using BlandAltman plots, with mean differences (systematic bias) calculated as FP - CJ and FP - MT, respectively. All statistical analyses were performed using Statistical Package for the Social Sciences (SPSS) Version 22 (IBM Corp, Armonk, NY). Bland Altman plots were constructed using Microsoft Excel 2013 (Microsoft Corp, Redmond, WA). Statistical significance (twotailed) was set at an alpha level of 0.05 . 


\section{1 \\ Results}

182

Thirty jump heights registered by each device were analysed. Mean jump heights

183

184

185

186

187

188

189

190

191

192

193

194

195

196

197

198

199

200

201

202
INSERT FIGURE 1 ABOUT HERE

INSERT FIGURE 2 ABOUT HERE

Figure 3 shows a strong, statistically significant correlation between jump height derived from the MT and FP $(r=0.66, p<0.01)$. Paired samples t-test revealed a statistically significant difference between jump height derived from the MT and FP $(\mathrm{t}(29)=4.09 ; \mathrm{p}<$ $0.001 ; d=0.64$, moderate). Bland Altman plot depicting limits of agreement between MT and FP is shown in Figure 4. Compared to FP, MT overestimates CMJ height by $4.07 \pm 5.45$ $\mathrm{cm}$. Fisher's r-z transformation revealed no statistically significant difference between the correlation between $\mathrm{CJ}$ and FP, and between MT and FP $(z=-0.06, p>0.05)$ 
203

INSERT FIGURE 3 ABOUT HERE

204

205

INSERT FIGURE 4 ABOUT HERE

206

207 


\section{Discussion}

209 The present study examined the validity of the ChronoJump contact mat and

210 Myotest accelerometer system compared to a laboratory-based force platform for

211 measuring CMJ height, in recreationally active males and females. The main findings of this

212 study were that: (1) CMJ height derived from both $\mathrm{CJ}$ and MT was strongly and significantly

213 correlated with FP-derived measures; (2) CJ derived measures of CMJ were not significantly

214 different to FP-derived measures, but MT-derived measures were; and (3) MT overestimates

215 CMJ height, whilst the CJ marginally underestimates CMJ height, compared to the FP.

The findings from the present study are in agreement with the those reported by

218 Castagna and colleagues (Castagna et al., 2013) who found the difference between FP and

219 an optical-based measure of flight time, to be small $(d=0.09)$, while differences between the

220 MT and FP were moderate $(d=0.54)$. Interestingly the present study, and that of Castagna

221 and colleagues (2013), observed both a moderate effect size and larger systematic bias

222 when using the MT, than a contact mat or optical timing system to assess CMJ height

223 against a force platform. From a practical point of view, these results suggest the two

224 systems provide different results, with the $\mathrm{CJ}$ measures of $\mathrm{CMJ}$ height closer to gold-

225 standard values, and subsequently more accurate. In contrast, the MT appears to be

226 affected by a greater systematic bias, which leads to an overestimation of CMJ height by

227 approximately $4 \mathrm{~cm}$. 
In the present study, the Bland Altman plot show a systematic bias of $-1.18 \pm 6.87 \mathrm{~cm}$

in CMJ height between the CJ and FP. This data suggest good levels of agreement, which

supports the validity of the $\mathrm{CJ}$ in measuring $\mathrm{CMJ}$ height when compared to the gold-

232

standard. Previous studies comparing CMJ height measures using differing contact mats

233

with force platforms (Enoksen, Tonnessen, \& Shalfawi, 2009; García-López et al., 2013;

Kenny \& Comyns, 2012) and a 3-dimensional camera system (Leard et al., 2007) report

mean differences ranging from $-1.3 \mathrm{~cm}$ to $2.8 \mathrm{~cm}$. The results of the present study compare

favourably with Garcia-Lopez and colleagues (2013) who reported CMJ height was

underestimated when using a contact mat compared to a force platform. In contrast, our

results are in disagreement with the findings of Enoksen and colleagues (2009) who

reported CMJ height was overestimated when comparing a contact mat with a force

platform. As Buckthorpe and colleagues (2012) noted, the likely reason for discrepancies in

$\mathrm{CMJ}$ height between contact mats and force platforms, is the methodology underpinning

flight time and initial velocity measurement. When performing a CMJ on a contact mat, the

timer starts when the subject leaves the ground, which may fail to capture the initial rise of

the centre of mass before take-off. Furthermore, the flight time method assumes the take-

off and landing positions will be identical, ensuring the duration of the ascending and

descending phases of flight time are the same (Buckthorpe et al., 2012).In the present study,

these discrepancies are evident by the presence of outliers. For example, Figure 1 shows

one data point where $\mathrm{CMJ}$ height determined using the $\mathrm{CJ}$ was approximately $15 \mathrm{~cm}$, yet was

threshold to determine contact times on the FP, the use of poor landing technique, or lack 
252 systematic bias observed with the $\mathrm{CJ}$ and FP measures of CMJ height observed in the current 253 study.

Similar to the $\mathrm{CJ}$, the present study showed a strong significant correlation between

MT and FP. However, mean jump heights were statistically significantly different. As compared CMJ height assessed via MT, with both portable (Choukou et al., 2014; Mauch et al., 2014) and in-built force platforms (Monnet, Decatoire, \& Lacouture, 2014), reporting mean differences between -1.09 to $4.8 \mathrm{~cm}$. Similar to our findings, Monnet and colleagues (2014) reported a mean difference of $4.8 \pm 6.90 \mathrm{~cm}$ when comparing CMJ height between the Myotest and a FP. The overestimation of CMJ height by the MT may be related to errors in flight time estimation (Choukou et al., 2014). Choukou and colleagues (2013) report that flight time is the time between maximal vertical velocity and minimal vertical velocity after touchdown. This equation cannot be verified from the device manual and to the best of our knowledge, no published study has fully described the known method for deriving flight time from accelometric data collected using the Myotest Pro device employed in the present study. Additionally, velocity is obtained from the integration of acceleration data and this mathematical manipulation may introduce errors magnified by downstream 270 calculations, or as a result of variations in $\mathrm{CMJ}$ technique.

Alternatively, rotational effects on the MT, due to its placement on the hip may account for this overestimation, since any rotation of the pelvis during the $\mathrm{CMJ}$ will affect tracking of the body's centre of mass and thus its measurement of CMJ height (Mauch et al., 
2014). Interestingly, Monnet and colleagues (2014) demonstrated a reduction in CMJ height

bias from $4.8 \pm 9.4 \mathrm{~cm}$ to $-1.3 \pm 9.2 \mathrm{~cm}$ after defining a new threshold to detect take-off and landing times. Thus, in the present study it is unclear if the measurement itself or the applied algorithm is producing the discrepancy in CMJ height. Nonetheless, this is a limitation that practitioners using the device need be aware of.

having been engaged in regular sport or recreational activities for a minimum of 12 months.

of sample homogeneity. The present study did not collect training age history as a demographic variable; rather, engaged recreationally active participants, operationalised as Training history has recently been shown to affect the reliability of CMJ performance. Lombard and colleagues (2017) reported that reliability was greater for participants more accustomed to strength training. Therefore repeat testing is capable of detecting small differences in performance which may be clinically or functionally meaningful. Participants in the current study met the definition of 'trained' used by Lombard and colleagues (2017) based on training duration (>12 months), but not on training type (strength training specifically). Therefore replication of the present study in a more homogeneous athletic population may be warranted.

\section{Practical applications}

The present study compared CMJ performance using field measures (CJ and MT) with laboratory-based measures (FP) in a convenience sample of recreationally active University students. Results showed that the $\mathrm{CJ}$ is a valid, portable device to assess CMJ height. 
298 Moreover, the differences between the CJ and FP were trivial considering the practical

299 significance. In contrast, whilst the MT also demonstrates good validity, this device showed

300 a moderate difference in CMJ height when compared to the FP. Despite these important

301 findings, the confidence intervals are wide for both the $\mathrm{CJ}(12.10--9.73 \mathrm{~cm})$, and the MT

$302(6.83--14.93 \mathrm{~cm})$. Therefore the devices may lack the sensitivity to detect small changes in

303 performance. Nonetheless, the use of the $\mathrm{CJ}$ in the present study offered several advantages

304 for the assessment of CMJ height in the field, compared to the MT. These include lower

305 purchase costs, reduced time to complete the test, and more rapid reporting of results. In

306 addition, the software is free and open source, runs on multiple operating systems, and is

307 available in multiple languages. Whilst the MT offers the advantage of being able to be used

308 on a wider variety of surfaces, the significant overestimates of CMJ height, and the use of a

309 Velcro belt to secure the MT unit to the subjects' hip reduces its potential usefulness.

310 Collectively, this suggests the use of the MT for the rapid field evaluation of CMJ height may

311 be limited compared to $\mathrm{CJ}$. The results of the present study may have direct implications for

312 strength and conditioning professionals, sport scientists and coaches who do not have direct 313 access to performance laboratories.

\section{Conclusions}

Based on correlation coefficients, both the $\mathrm{CJ}$ and MT systems are valid instruments

for the field assessment of CMJ height. However, CMJ height assessed using the MT is

318 significantly different from that recorded using the FP. Additionally, the MT demonstrates

319 greater systematic bias compared to the CJ. Because of these differences in measurement

320 outcomes, coaches and clinicians should use caution when interpreting and comparing data 
321 from these devices. Users should be aware of systematic bias in both devices. To minimise

322 bias and improve reliability, consistent measurement conditions including the use of the

323 same device should be employed for all testing occasions. 
331 References

332 Balsalobre-Fernández, C., Glaister, M., \& Lockey, R. A. (2015). The validity and reliability

333 of an iPhone app for measuring vertical jump performance. Journal of Sports Science, 3(15),

334 1574-1579. doi: 10.1080/02640414.2014.996184

335 Bosco, C., Luhtanen, P., \& Komi, P. V. (1983). A simple method for measurement of

336 mechanical power in jumping. European Journal of Applied Physiology and Occupational

337 Physiology, 50(2), 273-282.

338 Bosquet, L., Berryman, N., \& Dupuy, O. (2009). A comparison of 2 optical timing systems

339 designed to measure flight time and contact time during jumping and hopping. Journal of

340 Strength and Conditioning Research, 23(9), 2660-2665. doi: 10.1519/JSC.0b013e3181b1f4ff

341 Buckthorpe, M., Morris, J., \& Folland, J. P. (2012). Validity of vertical jump measurement

342 devices. Journal of Sports Sciences, 30(1), 63-69. doi: 10.1080/02640414.2011.624539

343 Carlock, L. M., Smith, S. L., Hartman, M. J., Morris, R. T., Ciroslan, D. A., Pierce, K. C., . . .

344 Stone, M. H. (2004). The relationship between vertical jump power estimates and

345 weightlifting ability: A field-test approach. Journal of Strength and Conditioning Research,

346 18(3), 534-539. doi:10.1519/R-13213.1

347 Casartelli, N., Muller, R., \& Maffiuletti, N. A. (2010). Validity and reliability of the Myotest 
348 accelerometric system for the assessment of vertical jump height. Journal of Strength and

349 Conditioning Research, 24(11), 3186-3193. doi:10.1519/JSC.0b013e3181d8595c

350 Castagna, C., Ganzetti, M., Ditroilo, M., Giovannelli, M., Rocchetti, A., \& Manzi, V. (2013).

351 Concurrent validity of vertical jump performance assessment systems. Journal of Strength

352 and Conditioning Research, 27(3), 761-768. doi:10.1519/JSC.0b013e31825dbcc5

353 Choukou, M. A., Laffaye, G., \& Taiar, R. (2014). Reliability and validity of an accele

354 rometric system for assessing vertical jumping performance. Biology of Sport, 31(1), 55-62.

355 doi: $10.5604 / 20831862.1086733$

356 Cohen, J. (1988). Statistical power analysis for the behavioral sciencies (2nd ed.). Hillsdale,

357 N.J.: Earlbaum.

358 Comfort, P., Stewart, A., Bloom, L., \& Clarkson, B. (2014). Relationships between strength,

359 sprint, and jump performance in well-trained youth soccer players. Journal of Strength and

360 Conditioning Research, 28(1), 173-177. doi:10.1519/JSC.0b013e318291b8c7

361 de Blas, X., Riu, J. M. P., del Amo, J. L. L., \& Bálic, M. G. (2012). Creation and validation

362 of chronojump-boscosystem: A free tool to measure vertical jumps. RICYDE. Revista

363 Internacional de Ciencias del Deporte, 8(30), 334-356. doi:10.5232/ricyde2012.03004

364 Enoksen, E., Tonnessen, E., \& Shalfawi, S. (2009). Validity and reliability of the Newtest 
365 Powertimer 300-series testing system. Journal of Sports Sciences, 27(1), 77-84. doi:

$366 \quad 10.1080 / 02640410802448723$

367 ESSA. (2011). Adult pre-exercise screening system. Exercise and Sports Science Australia,

368 Brisbane.

369 Evans, J. D. (1996). Straightforward statistics for the behavioral sciences. Pacific Grove, CA:

370 Brooks/Cole.

371 Fernandez-Santos, J. R., Ruiz, J. R., Cohen, D. D., Gonzalez-Montesinos, J. L., \& Castro

372 Pinero, J. (2015). Reliability and validity of tests to assess lower-body muscular power in

373 children. Journal of Strength and Conditioning Research, 29(8), 2277-2285.

374 doi:10.1519/jsc.0000000000000864

375 Gabbett, T. J. (2002). Physiological characteristics of junior and senior rugby league players.

376 British Journal of Sports Medicine, 36(5), 334-339. doi:10.1136/bjsm.36.5.334

377 García-López, J., Morante, J. C., Ogueta-Alday, A., \& Rodríguez-Marroyo, J. A. (2013). The

378 type of mat (contact vs. photocell) affects vertical jump height estimated from flight time.

379 Journal of Strength and Conditioning Research, 27(4), 1162-1167.

380 doi:10.1519/JSC.0b013e31826520d7

381 Garcia-Pinillos, F., Soto-Hermoso, V. M., \& Latorre-Roman, P. A. (2015). Acute effects of

382 extended interval training on countermovement jump and handgrip strength performance 
383 in endurance athletes: postactivation potentiation. Journal of Strength and Conditioning

384 Research, 29(1), 11-21. doi:10.1519/JSC.0000000000000591.

385 Gathercole, R., Sporer, B., Stellingwerff, T., \& Sleivert, G. (2015). Alternative

386 countermovement-jump analysis to quantify acute neuromuscular fatigue. International

387 Journal of Sports and Physiological Performance, 10(1), 84-92.

388 doi:10.1519/jsc.0000000000000912

389 Holsgaard Larsen, A., Caserotti, P., Puggaard, L., \& Aagaard, P. (2007). Reproducibility and

390 relationship of single-joint strength vs multi-joint strength and power in aging individuals.

391 Scandinavian Journal of Medicine and Science in Sports, 17(1), 43-53. doi:10.1111/j.1600-

$392 \quad 0838.2006 .00560 . x$

393 Janot, J. M., Beltz, N. M., \& Dalleck, L. D. (2015). Multiple off-ice performance variables

394 predict on-ice skating performance in male and female division III ice hockey players.

395 Journal of Sports Science and Medicine, 14(3), 522-529.

396 Kenny, I. C., A, O. C., \& Comyns, T. M. (2012). Validation of an electronic jump mat to

397 assess stretch-shortening cycle function. Journal of Strength and Conditioning Research,

398 26(6), 1601-1608. doi:10.1519/JSC.0b013e318234ebb8

399 Leard, J. S., Cirillo, M. A., Katsnelson, E., Kimiatek, D. A., Miller, T. W., Trebincevic, K., \&

400 Garbalosa, J. C. (2007). Validity of two alternative systems for measuring vertical jump 
401 height. Journal of Strength and Conditioning Research, 21(4), 1296-1299. doi:10.1519/r-

$402 \quad 21536.1$

403 Lombard, W., Reid, S., Pearson, K., \& Lambert, M. (2017). Reliability of metrics associated

404 with a counter-movement jump performed on a force plate. Measurement in Physical

405 Education and Exercise Science, 21(4), 235-243. doi:10.1080/1091367X.2017.1354215

406 Linthorne, N. P. (2001). Analysis of standing vertical jumps using a force platform. American

407 Journal of Physics, 69(11), 1198-1204. doi:10.1119/1.1397460

408 Mauch, M., Praxisklinik, R., Hans-Joachim, R., Praxisklinik, R., Xaver, J., \& Praxisklinik, R.

409 (2014) Reliability and validity of two measurement systems in the quantification of jump

410 performance. Schweizerische Zeitschrift für Sportmedizin und Sporttraumatologie, 62, 57-63.

411 Monnet, T., Decatoire, A., \& Lacouture, P. (2014). Comparison of algorithms to determine

412 jump height and flight time from body mounted accelerometers. Sports Engineering, 17(4),

413 249-259. doi: 10.1007/s12283-014-0155-1

414 Pagaduan, J. C., \& De Blas, X. (2004). Reliability of countermovement jump performance on

415 chronojump-boscosystem in male and female athletes. Sports SPA, 10(2), 5-8.

416 Rittweger, J., Schiessl, H., Felsenberg, D., \& Runge, M. (2004). Reproducibility of the

417 jumping mechanography as a test of mechanical power output in physically competent adult 
418 and elderly subjects. Journal of the American Geriatrics Society, 52(1), 128-131. doi:

$419 \quad 10.1111 / j .1532-5415.2004 .52022 . x$

420 Shetty, A. B., \& Etnyre, B. R. (1989). Contribution of arm movement to the force

421 components of a maximum vertical jump. Journal of Orthopedic and Sports Physical

422 Therapy, 11(5), 198-201.

423 West, D. J., Owen, N. J., Jones, M. R., Bracken, R. M., Cook, C. J., Cunningham, D. J., .. .

424 Kilduff, L. P. (2011). Relationships between force-time characteristics of the isometric

425 midthigh pull and dynamic performance in professional rugby league players. Journal of

426 Strength and Conditioning Research, 25(11), 3070-3075.

427 doi:10.1519/JSC.0b013e318212dcd5

428 Wisloff, U., Castagna, C., Helgerud, J., Jones, R., \& Hoff, J. (2004). Strong correlation of

429 maximal squat strength with sprint performance and vertical jump height in elite soccer

430 players. British Journal of Sports Medicine, 38(3), 285-288. doi: 10.1136/bjsm.2002.002071 
432 Figure 1. Correlation between $\mathrm{CMJ}$ jump height measured with $\mathrm{CJ}$ and FP

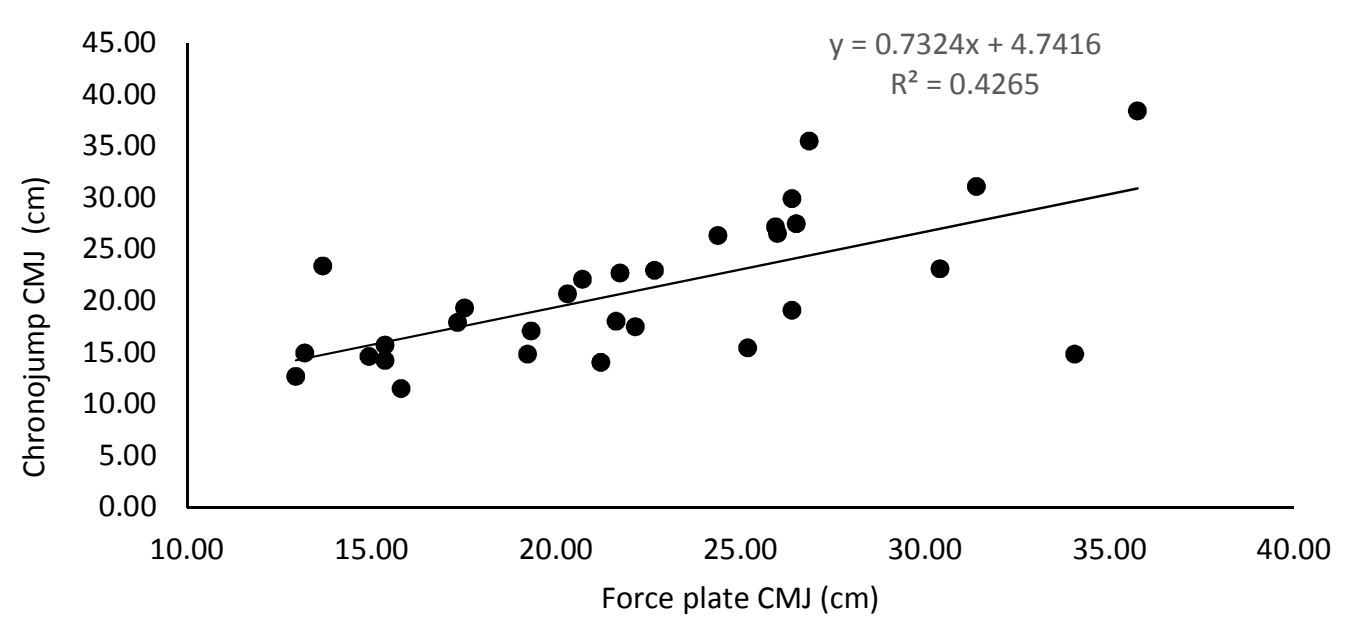

433

434 
2

3

4

5

6

7

8

9

10

11

12

13

14

15

16

17

18

19

20

21

22

23

24

25

26

27

28

29

30

31

32

33

34

35

36

37

38

39

40

41

42

43

44

45

46

47

48

49

50

51

52

53

54

55

56

57

58

59

60

435 Figure 2. Bland and Altman Plot $(n=30)$ comparing CJ and FP. Mean difference $=1.18 \pm 5.46$

$436 \mathrm{~cm}, 95 \% \mathrm{Cl}=12.10--9.73 \mathrm{~cm}$

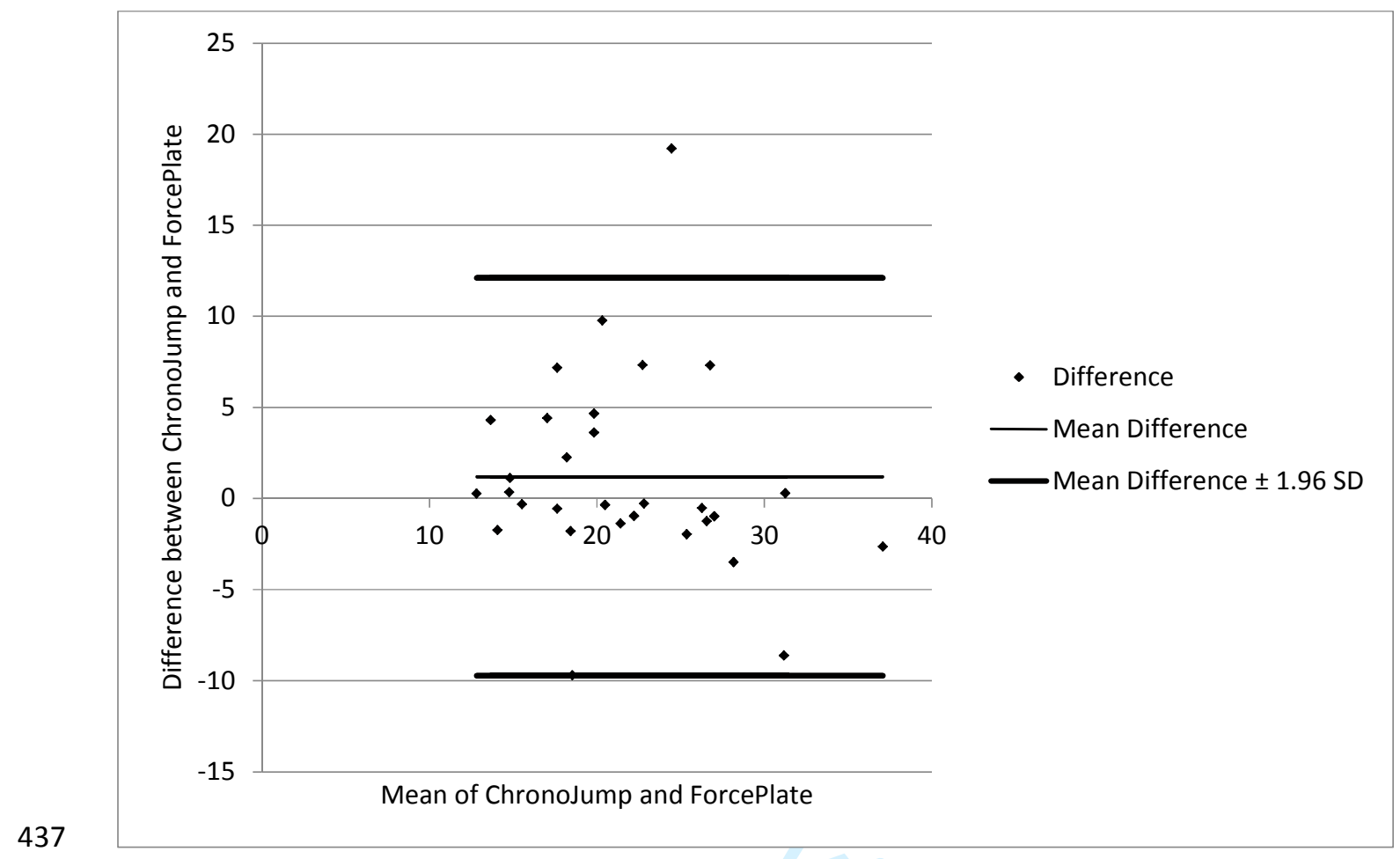

438 
439 Figure 3. Correlation between CMJ jump height measured with MT and FP

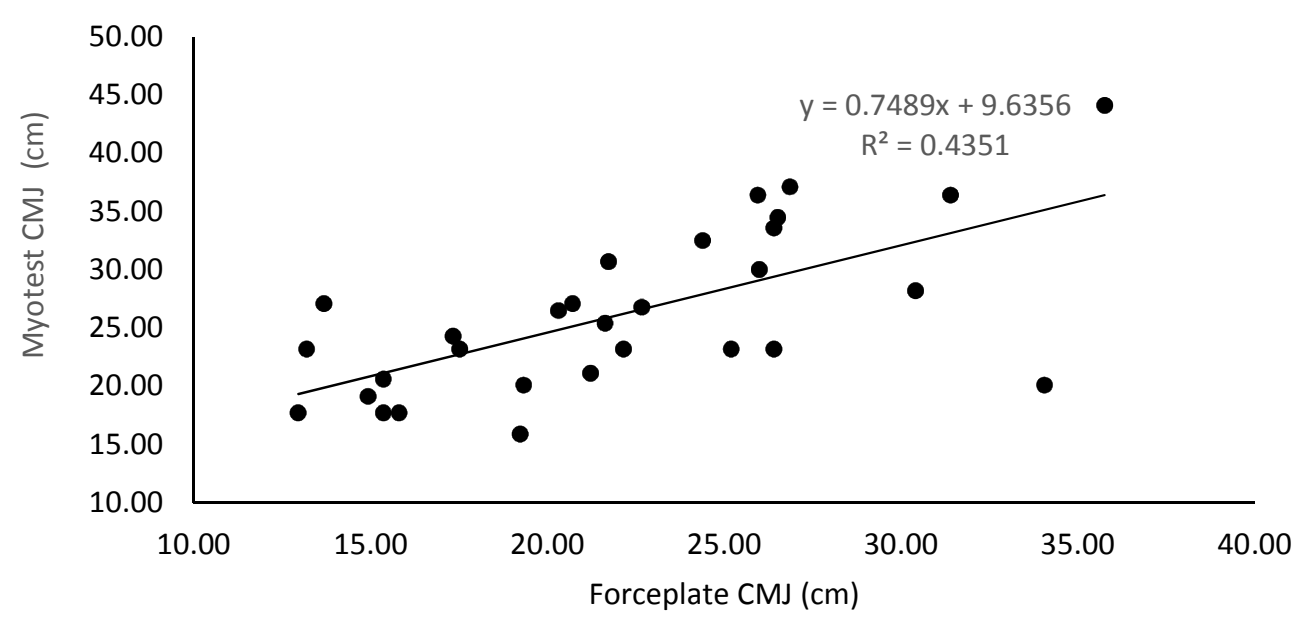

440

441 
2

3

4

5

6

7

8

9

10

11

12

13

14

15

16

17

18

19

442 Figure 4. Bland and Altman Plot $(n=30)$ comparing MT and FP. Mean difference $=-4.07 \pm$

$443 \quad 5.45 \mathrm{~cm}, 95 \% \mathrm{Cl}=6.83--14.93 \mathrm{~cm}$

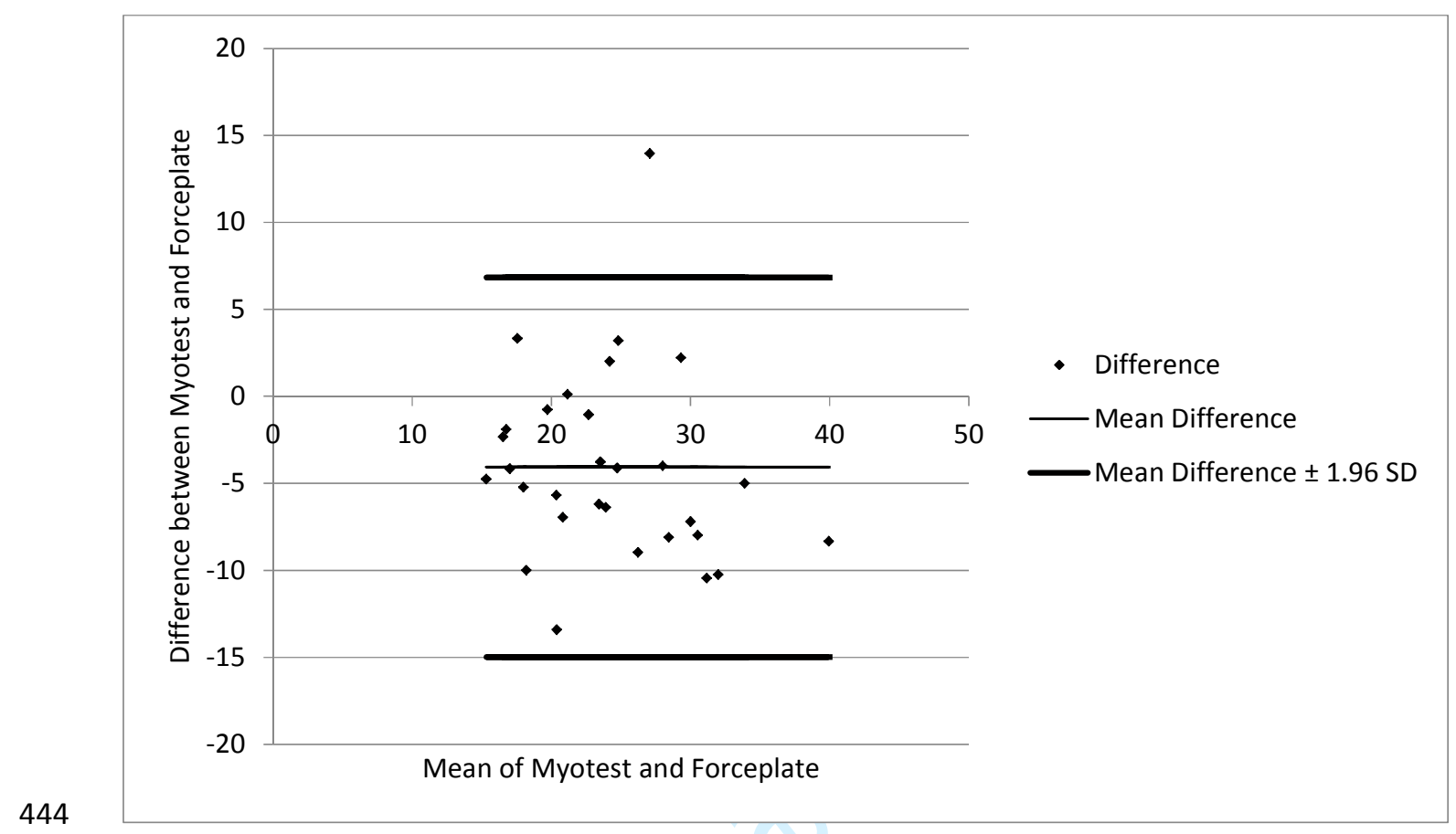

